IZA DP No. 720

Labour Market Regulation, ProductivityImproving R\&D and Endogenous Growth

Tapio Pal okangas

February 2003 


\title{
Labour Market Regulation, Productivity-Improving R\&D and Endogenous Growth
}

\author{
Tapio Palokangas \\ University of Helsinki \\ and IZA Bonn
}

Discussion Paper No. 720

February 2003

\author{
IZA \\ P.O. Box 7240 \\ D-53072 Bonn \\ Germany \\ Tel.: +49-228-3894-0 \\ Fax: +49-228-3894-210 \\ Email: iza@iza.org
}

This Discussion Paper is issued within the framework of IZA's research area Welfare State and Labor Market. Any opinions expressed here are those of the author(s) and not those of the institute. Research disseminated by IZA may include views on policy, but the institute itself takes no institutional policy positions.

The Institute for the Study of Labor (IZA) in Bonn is a local and virtual international research center and a place of communication between science, politics and business. IZA is an independent, nonprofit limited liability company (Gesellschaft mit beschränkter Haftung) supported by the Deutsche Post AG. The center is associated with the University of Bonn and offers a stimulating research environment through its research networks, research support, and visitors and doctoral programs. IZA engages in (i) original and internationally competitive research in all fields of labor economics, (ii) development of policy concepts, and (iii) dissemination of research results and concepts to the interested public. The current research program deals with (1) mobility and flexibility of labor, (2) internationalization of labor markets, (3) welfare state and labor market, (4) labor markets in transition countries, (5) the future of labor, (6) evaluation of labor market policies and projects and (7) general labor economics.

IZA Discussion Papers often represent preliminary work and are circulated to encourage discussion. Citation of such a paper should account for its provisional character. A revised version may be available on the IZA website (www.iza.org) or directly from the author. 
IZA Discussion Paper No. 720

February 2003

\section{ABSTRACT \\ Labour Market Regulation, Productivity-Improving R\&D and Endogenous Growth}

We present a growth model in which R\&D increases productivity, union-firm bargaining determines the distribution of rents and the government can support unions by labour market regulation. We show that if unions are initially very strong, regulation increases only the workers' profit share and has no impact on employment and growth. Otherwise, regulation increases wages. Because firms try to escape this cost increase through the improvement of productivity by R\&D, the economy grows faster. Regulation (deregulation) is desirable when the growth rate is below (above) some critical level.

JEL Classification: $\quad$ O40, J50

Keywords: endogenous growth, labour unions, regulation

Tapio Palokangas

Department of Economics

University of Helsinki

P.O. Box 54

00014 Helsinki

Finland

Tel.: +358919124891

Fax: +358 919124877

Email: Tapio.Palokangas@helsinki.fi 


\section{Introduction}

The problem of high unemployment and low growth, a phenomenon called 'Eurosclerosis', is one of the most pressing economic problems in the European Union. Recently, the OECD Jobs Study took a stand on this problem by arguing that strengthening competitive forces in the economy would foster economic growth and reduce unemployment. ${ }^{1}$ To examine this, I establish an endogenous-growth model in which unemployment is caused by efficiency wages and union-firm bargaining. Following Blanchard and Giavazzi (2001), we think of labour market regulation (deregulation) as increasing (decreasing) the bargaining power of the labour unions.

The review of the literature shows that the relationship between growth and labour market regulation can be highly institution-specific. Peretto (2000) examines the effects of regulation by a product-variety model in which labour is employed only in production and final goods can be directly used in $R \& D$. He also assumes that unions completely ignore that the increase of their wages affects productivity through $R \& D$. Peretto's main assertion is that a fall in union power promotes $R \& D$ and growth through a higher profit margin. In contrast, we assume that labour is used both in production and $R \& D$ and unions take into account also the effects through $R \& D$.

Palokangas $(1996,2000)$ introduces wage bargaining into Romer's (1990) product-variety model in which $R \& D$ employs labour only but final goods are produced from skilled labour, unskilled labour and intermediate products. He shows that higher relative union bargaining power leads to a higher growth rate as follows. Because $R \& D$ employs skilled labour and increases aggregate labour income, the union does not accept any agreement causing unemployment of skilled labour. With full employment of skilled labour, the increase in union power speeds up economic growth through a transfer of skilled labour from the production of final goods to $R \& D$. This conclusion results however from three specific assumptions. First, bargaining is carried out at the level of an industry or the economy rather than at the level of a single firm. Second, there are two separate labour inputs, skilled and un-

\footnotetext{
${ }^{1}$ Cf. OECD (1994), pp. 23 and 53: 'Establishing a competitive environment could, therefore, improve job prospects by both eliminating wage premia and encouraging output expansion.'
} 
skilled labour, which are both organized in the same labour union. Third, there are no efficiency wages. In contrast, we assume union-firm bargaining, homogeneous labour and efficiency wages.

This paper is organized as follows. Labour market imperfections, which play a crucial role in the analysis, are presented in section 2 . Sections 3 and 4 specify the behaviour of consumers and high-tech firms. Section 5 considers union-firm bargaining and section 6 optimal labour market regulation.

\section{The labour market}

The economy consists of two sectors that produce consumption goods. The high-tech sector contains a fixed number $n$ of similar price-setting firms (indexed $i=1, \ldots, n)$, each of which manufactures one variety of the differentiated products, produces new knowledge and uses labour, knowledge and some non-traded factor as inputs. The traditional sector comprises competitive firms that produce unit of output from one labour unit. A high-tech firm and a firm-specific union bargain over the wage and the workers' profit share taking macroeconomic variables (e.g. the price level, aggregate consumption, the expected labour income elsewhere) as given. Labour market regulation determines relative union bargaining power.

We assume that labour supply $N$ is fixed, for simplicity. Because the traditional sector is competitive, we obtain the equilibrium condition

$$
L+\sum_{i=1}^{n} l_{i}=N
$$

where $L$ is the employment of physical labour in the traditional sector and $l_{i}$ is that in the $i$ th high-tech firm (hereafter firm $i$ ). Firm $i$ pays a share $s_{i}$ of its profit $\pi_{i}$ to its workers in proportion to employment. Since the profit share is non-negative for both parties, we obtain

$$
0 \leq s_{i} \leq 1
$$

The total wage is then given by

$$
v_{i} \doteq w_{i}+s_{i} \pi_{i} / l_{i},
$$


where $w_{i}$ is the base wage and $s_{i} \pi_{i} / l_{i}$ the profit share per worker. Labour income $U_{i}$ in firm $i$ is equal to the total wage (3) times employment $l_{i}$ :

$$
U_{i} \doteq v_{i} l_{i}=w_{i} l_{i}+s_{i} \pi_{i}
$$

When a worker quits high-tech firm $i$, his expected income elsewhere in the economy, $v_{-j}$, is given by the probability-weighed average

$$
v_{-i} \doteq \sum_{j \neq i} v_{j} \frac{l_{j}}{N-l_{i}}+\varpi \frac{L}{N-l_{i}}=\frac{1}{N-l_{i}}\left[\sum_{j \neq i} v_{j} l_{j}+\varpi L\right],
$$

where $v_{i}$ is the total wage in firm $j, l_{j} /\left(N-l_{i}\right)$ the probability of getting a job in firm $j, \varpi$ the wage in the traditional sector and $L /\left(N-l_{i}\right)$ the probability of being employed by the traditional sector.

An employee in firm $i$ works the harder, the higher his wage $v_{i}$ relative to his prospective earnings elsewhere, $v_{-i}$. Consequently, a worker's effort in firm $i, E_{i}$, increases with the ratio $v_{i} / v_{-i}{ }^{2}$

$$
E_{i}=E\left(v_{i} / v_{-i}\right), \quad E^{\prime}>0, \quad E(1)=0 .
$$

Efficient labour input in firm $i$ is then given by

$$
x_{i}=E_{i} l_{i}
$$

Because a worker would not make any effort if he earned the same income outside the firm, $E(1)=0$, there must be $E_{i}>0$ and $v_{i}>v_{-i} \cdot{ }^{3}$

If firm $i$ could alone choose its base wage $w_{i}$ and profit share $s_{i}$, it would give up profit sharing, $s_{i}=0$, and minimize the unit labour cost $v_{i} / E_{i}=$ $v_{i} / E\left(v_{i} / v_{-i}\right)$ by the wage $v_{i}=w_{i}$, given a worker's expected income elsewhere $v_{-i}$. This defines a non-union wage,

$$
\tilde{v}_{i}=\arg \min _{v_{i}}\left[v_{i} / E\left(v_{i} / v_{-i}\right)\right]=\epsilon v_{-i} \text {, where } \epsilon>1 \text { and } \epsilon E^{\prime}(\epsilon)=E(\epsilon) .
$$

Because a worker is willing to join a labour union only if this increases his income, the total wage for a member, $v_{i}$, must exceed the non-union wage

\footnotetext{
${ }^{2}$ This function is constructed in line with Solow (1979), Summers (1988) and Garino and Martin (2000). However, the results in this paper hold even if the effort per worker is wholly inflexible, $E^{\prime} \equiv 0$, provided that there is unemployment in the equilibrium.

${ }^{3}$ This property simplifies the analysis by eliminating full employment in the model.
} 
$\tilde{v}_{i}=\epsilon v_{-i}$. Given this and (8), a wage increase raises unit labour cost $v_{i} / E_{i}:{ }^{4}$

$$
\frac{\partial}{\partial v_{i}}\left[\frac{v_{i}}{E\left(v_{i} / v_{-i}\right)}\right]=\frac{1}{E}\left[1-\frac{E^{\prime}}{E} \frac{v_{i}}{v_{-i}}\right]>0
$$

The agents act as players in the following extensive game. First, the government determines relative union bargaining power. Second, each unionfirm pair bargains over the wage and the workers' profit share. Third, firms decide on output and $R \& D$. Fourth, consumers decide on spending and saving. The model is solved by backward induction in sections 3-6.

\section{Consumers}

Because all consumers are price takers, we can aggregate them into a single agent. This representative consumer's intertemporal utility is given by

$$
\int_{0}^{\infty} \frac{1}{1-\sigma}\left[c^{1-\sigma}-1\right] e^{-\rho t} d t \text { with } \rho>0, \sigma>0 \text { and } \sigma \neq 1,
$$

where $c$ is an index of composite consumption of high-tech goods, $1 / \sigma$ the intertemporal elasticity of substitution, $\rho$ the subjective discount rate and $t$ time. The index $c$ is produced from high-tech and traditional goods according to Cobb-Douglas technology. The elasticity of substitution between any two of the high-tech goods, $\mu>1$, is constant. These assumptions imply

$$
c=y^{\xi} L^{1-\xi}, \quad 0<\xi<1, \quad y=\left[\frac{1}{n} \sum_{i=1}^{n} y_{i}^{1-1 / \mu}\right]^{\mu /(\mu-1)}, \quad \mu>1
$$

where $y_{i}$ represents the quantity of high-tech good $i$ consumed, $y$ the index of the high-tech goods, $L$ the quantity of traditional goods consumed and parameter $\xi$ the relative weight of high-tech goods in consumption.

The consumer decides on how to divide his spending over the goods. We choose the consumption price for the composite high-tech good $y$ as the numeraire. Because the traditional sector produces one unit of output from

\footnotetext{
${ }^{4}$ This result is necessary for the uniqueness of the equilibrium. Otherwise, there could be two equilibria: one with a high wage $v_{i}$ and high effort $E_{i}$, and the other with a low wage and low effort.
} 
one labour unit, its output price is equal to its wage $\varpi$. Given the CobbDouglas function in (10), we then obtain

$$
\varpi L / \xi=y /(1-\xi)=P c, \quad P=\zeta \varpi^{1-\xi},
$$

where $\zeta>0$ is a constant. Given the $C E S$ function in (10), we obtain the price $p_{i}$ for high-tech good $i$ as a function of the output of the good, $y_{i}$, and the index of high-tech output, $y$, with the following properties:

$$
p_{i}\left(y_{i}, y\right)=\frac{\partial y}{\partial y_{i}}=\frac{1}{n}\left(\frac{y}{y_{i}}\right)^{1 / \mu} \quad \sum_{i} p_{i} y_{i}=y, \quad \frac{\partial\left(p_{i} y_{i}\right)}{\partial y_{i}}=\left(1-\frac{1}{\mu}\right) p_{i} .
$$

The consumer takes the interest rate $r$, the consumption price $P$ and his income $I$ as given and maximizes utility (9) subject to the accumulation of wealth $\Omega$ over time, $\dot{\Omega} \doteq d \Omega / d t=r \Omega+I-P c$, where $c$ is consumption. In the steady state, this maximization yields

$$
g \doteq \dot{c} / c=(r-\rho) / \sigma
$$

where $g$ is the growth rate of consumption. Solving for the interest rate yields

$$
r=\rho+\sigma g
$$

Because in the steady state the demand for labour in the traditional sector, $L$, is constant, conditions (11) and (13) imply

$$
\frac{\dot{y}}{y}=\frac{\dot{\varpi}}{\varpi}=\frac{\dot{P}}{P}+\frac{\dot{c}}{c}=(1-\xi) \frac{\dot{\varpi}}{\varpi}+\frac{\dot{c}}{c}=(1-\xi) \frac{\dot{y}}{y}+g \text { and } \frac{\dot{y}}{y}=\frac{g}{\xi} .
$$

\section{High-tech firms}

The production and management of each product requires its own productspecific knowledge. Because a high-tech firm cannot directly apply techniques and procedures developed by other high-tech firms, these being tailored to the specific situation of others, product-specific knowledge can be accumulated only through product-specific $R \& D$ targeted at one product. ${ }^{5}$ Firm $i$ 's productivity both in production and in $R \& D$ is in fixed proportion to its

\footnotetext{
${ }^{5}$ The process of innovation in the model is a minor modification of that in Smulders and Van der Klundert (1995) and Van Schaik and De Groot (1998).
} 
stock of knowledge $h_{i}$, which is accumulated by $R \& D$. Its output $y_{i}$ and the increase in its productivity, $\dot{h}_{i}$, are then given by

$$
\begin{aligned}
& y_{i}=m_{i} h_{i}, \\
& \dot{h}_{i}=z_{i} h_{i},
\end{aligned}
$$

where $m_{i}$ and $z_{i}$ are intermediate inputs in production and $R \& D$.

Firm $i$ possesses a fixed amount of non-traded input and employs the amount $x_{i}$ of efficient labour. Both $m_{i}$ and $z_{i}$ can be produced from these two inputs with constant returns to scale. On the assumptions that there is no factor intensity reversal and the increase in efficient labour $x_{i}$ increases output, the increase in $x_{i}$ must decrease $R \& D$ by Rybczynski's theorem. The resulting Rybczynski line can be expressed by two monotonous functions:

$$
m_{i}=m\left(x_{i}\right), \quad m^{\prime}>m_{i} / x_{i}>0, \quad z_{i}=z\left(x_{i}\right), \quad z^{\prime}<0 .
$$

Given the inverse demand function in (12), we obtain profits

$$
\pi_{i}=p_{i}\left(y_{i}, y\right) y_{i}-w_{i} l_{i}
$$

The firm chooses the employment of efficient labour, $x_{i}$, to maximize the present value of the flow of profits $\int_{0}^{\infty} \pi_{i} e^{-r t} d t$, where $r$ is the interest rate, subject to the accumulation of knowledge (17), given the base wage $w_{i}$, the effort per worker, $E_{i}$, and aggregate demand $y$. Given (12), (16), (18) and (19), it is equivalent to maximize at each moment of time the Hamiltonian

$$
\begin{aligned}
\mathcal{H}_{i} & =\pi_{i}+q_{i} \dot{h}_{i}=p_{i} y_{i}-w_{i} l_{i}+q_{i} \dot{h}_{i}=p_{i}\left(y_{i}, y\right) y_{i}-\left(w_{i} / E_{i}\right) x_{i}+q_{i} z_{i} h_{i} \\
& =p_{i}\left(m\left(x_{i}\right) h_{i}, y\right) m\left(x_{i}\right) h_{i}-\left(w_{i} / E_{i}\right) x_{i}+q_{i} z\left(x_{i}\right) h_{i}
\end{aligned}
$$

by $x_{i}$, where the shadow price of knowledge, $q_{i}$, evolves according to

$$
\dot{q}_{i}=r q_{i}-\frac{\partial \mathcal{H}_{i}}{\partial h_{i}}=\left(r-z_{i}\right) q_{i}-\frac{\partial\left(p_{i} y_{i}\right)}{\partial y_{i}} m_{i}, \quad \lim _{t \rightarrow \infty} q_{i} h_{i} e^{-\rho t}=0 .
$$

To explain this equation, we write it as follows:

$$
r-\frac{\dot{q}_{i}}{q_{i}}=z_{i}+\frac{\partial\left(p_{i} y_{i}\right)}{\partial y_{i}} \frac{m_{i}}{q_{i}} .
$$

Assume that the firm increases its stock of knowledge $h_{i}$ by one unit. Output then increases by $m_{i}$ and, by multiplying this by the marginal revenue of 
output (in terms of knowledge), $\left(1 / q_{i}\right)\left[\partial\left(p_{i} y_{i}\right) / \partial y_{i}\right]$, we obtain the marginal revenue of knowledge in production, $\left(m_{i} / q_{i}\right)\left[\partial\left(p_{i} y_{i}\right) / \partial y_{i}\right]$. The marginal revenue of knowledge in $R \& D$ is given by $\partial \dot{h}_{i} / \partial h_{i}=z_{i}$. The sum of these must be equal to the marginal cost of knowledge, which (in terms of knowledge) consists of the interest rate $r$ minus capital gains $\dot{q}_{i} / q_{i}$.

The maximization of the Hamiltonian (20) by $z_{i}$ yields

$$
\frac{w_{i}}{E_{i}}=\left[\frac{\partial\left(p_{i} y_{i}\right)}{\partial y_{i}} m^{\prime}\left(x_{i}\right)+q_{i} z^{\prime}\left(x_{i}\right)\right] h_{i} .
$$

Because firm $i$ has only one accumulating asset $h_{i}$, it is always in the steady state where $\dot{y}_{i} / y_{i}=\dot{h}_{i} / h_{i}$ holds and inputs $m_{i}, z_{i}$ and $x_{i}$ are constants. With the normalization of the consumption price at unity, the output price $p_{i}$ and the shadow price $q_{i}$ are constants. Given this, (14), (17) and (21), we obtain

$$
\dot{y}_{i} / y_{i}=\dot{h}_{i} / h_{i}=z_{i}, \quad h_{i}(t)=h_{i}(0) e^{z_{i} t}, \quad \rho+\sigma g=r=z_{i}+\frac{\partial\left(p_{i} y_{i}\right)}{\partial y_{i}} \frac{m_{i}}{q_{i}} .
$$

Solving for $q_{i}$ from this yields

$$
q_{i}=\frac{\partial\left(p_{i} y_{i}\right)}{\partial y_{i}} \frac{m_{i}}{\rho+\sigma g-z_{i}} .
$$

Inserting this into (22) and noting (12) and (18), we obtain

$$
\begin{aligned}
\frac{w_{i}}{E_{i} p_{i}} & =\Phi_{i}\left(x_{i}, g, h_{i}\right) \doteq\left[m^{\prime}+\frac{z^{\prime} m_{i}}{\rho+\sigma g-z_{i}}\right] \frac{\partial\left(p_{i} y_{i}\right)}{\partial y_{i}} \frac{h_{i}}{p_{i}} \\
& =\left(1-\frac{1}{\mu}\right)\left[m^{\prime}\left(x_{i}\right)+\frac{z^{\prime}\left(x_{i}\right) m\left(x_{i}\right)}{\rho+\sigma g-z\left(x_{i}\right)}\right] h_{i} .
\end{aligned}
$$

The dependence of $w_{i} /\left(E_{i} p_{i}\right)$ on $x_{i}$ through (24) is ambiguous. We make the plausible assumption that given the stock of knowledge, $h_{i}$, and the growth rate $g$ (or the interest rate $r=\rho+\sigma g$ ), an increase in real unit labour cost $w_{i} /\left(E_{i} p_{i}\right)$ decreases the employment of efficient labour, $x_{i}$ :

$$
\partial \Phi_{i} / \partial x_{i}<0 .
$$

Given (7), (16), (18), (24) and (25), we define the ratio of base wages $w_{i} l_{i}$ to income as a function of employment $x_{i}$, and the growth rate $g$ :

$$
\begin{aligned}
& \phi_{i}\left(x_{i}, g\right) \doteq \frac{w_{i} l_{i}}{p_{i} y_{i}}=\frac{w_{i} x_{i}}{E_{i} p_{i} m_{i} h_{i}}=\frac{\Phi_{i}\left(x_{i}, g, h_{i}\right) x_{i}}{m\left(x_{i}\right) h_{i}} \in(0,1) \\
& \text { with } \frac{\partial \phi_{i}}{\partial x_{i}}=\frac{x_{i}}{m_{i} h_{i}} \frac{\partial \Phi_{i}}{\partial x_{i}}+\frac{\Phi_{i}}{h_{i}}\left(\frac{1}{m_{i}}-\frac{x_{i}}{m_{i}^{2}} m^{\prime}\right)<0
\end{aligned}
$$


Given $\mu>1,(12),(16),(19),(24)$, (23) and (26), we obtain the present values for the flows of output, wages and profits for firm $i, Y_{i}, W_{i}$ and $P_{i}$, as:

$$
\begin{aligned}
Y_{i}\left(x_{i}, g, y\right) & \doteq \int_{0}^{\infty} p_{i} y_{i} e^{-r t} d t=\frac{y^{1 / \mu}}{n} \int_{0}^{\infty} y_{i}^{1-1 / \mu} e^{-r t} d t \\
& =\frac{y^{1 / \mu}}{n} m_{i}^{1-1 / \mu} \int_{0}^{\infty} h_{i}^{1-1 / \mu} e^{-r t} d t \\
& =h_{i}(0)^{1-1 / \mu} \frac{y^{1 / \mu}}{n} m\left(x_{i}\right)^{1-1 / \mu} \int_{0}^{\infty} \exp \left\{\left[\left(1-\frac{1}{\mu}\right) z_{i}-r\right] t\right\} d t \\
& =h_{i}(0)^{1-1 / \mu} \frac{y^{1 / \mu}}{n} m\left(x_{i}\right)^{1-1 / \mu}\left[r-\left(1-\frac{1}{\mu}\right) z_{i}\right]^{-1} \\
& =h_{i}(0)^{1-1 / \mu} \frac{y^{1 / \mu}}{n} m\left(x_{i}\right)^{1-1 / \mu}\left[\rho+\sigma g-\left(1-\frac{1}{\mu}\right) z\left(x_{i}\right)\right]^{-1} \\
W_{i}\left(x_{i}, g, y\right) & \doteq \int_{0}^{\infty} w_{i} l_{i} e^{-r t} d t=\phi_{i} \int_{0}^{\infty} p_{i} y_{i} e^{-r t} d t=\phi_{i}\left(x_{i}, g\right) Y_{i}\left(x_{i}, g, y\right), \\
\Pi_{i}\left(x_{i}, g, y\right) & \doteq \int_{0}^{\infty} \pi_{i} e^{-r t} d t=Y_{i}\left(x_{i}, g, y\right)-W_{i}\left(x_{i}, g, y\right)
\end{aligned}
$$

\section{Union-firm bargaining}

Firm $i$ and a firm-specific union bargain over the wage $w_{i}$ and the workers' profit share $s_{i}$. We assume that in the case of a dispute there is no production, and consequently no labour income and no profits. The reference income is then zero for both the firm and the union. Some papers assume that the expected wage outside the firm is the union's reference point, ${ }^{6}$ but this is not quite in line with the microfoundations of the alternating offers game. Binmore, Rubinstein and Wolinsky (1986) state (pp. 177, 185-6) that the the reference income should not be identified with the outside option point. Rather, despite the availability of these options, it remains appropriate to identify the reference income with the income streams accruing to the parties in the course of the dispute. ${ }^{7}$ Accordingly, a worker's expected income elsewhere, $v_{-i}$, affects his effort in the workplace, $E_{i}$, but not the union's reference income.

\footnotetext{
${ }^{6}$ E.g. in Garino and Martin (2000).

${ }^{7}$ For example, if the dispute involves a strike, these income streams are the employee's income from temporary work, union strike funds, and similar sources, while the employer's income might derive from temporary arrangements that keeps the business running.
} 
The union attempts to maximize the present value $\mathcal{U}_{i}$ of labour income $U_{i}$ and the firm attempts to maximize the present value $\mathcal{P}_{i}$ of the owner's profit share $\left(1-s_{i}\right) \pi_{i}$. Given (4), (28) and (29), we obtain these targets as:

$$
\mathcal{U}_{i}\left(s_{i}, x_{i}, g, y\right)=\int_{0}^{\infty} U_{i} e^{-r t} d t=W_{i}+s \Pi, \quad \mathcal{P}_{i}\left(s_{i}, x_{i}, g, y\right)=\left(1-s_{i}\right) \Pi_{i}
$$

Because targets $\mathcal{U}_{i}$ and $\mathcal{P}_{i}$ are constants, the solution for the asymmetric Nash bargain is obtained through maximizing the Generalized Nash Product $\mathcal{U}_{i}^{\alpha} \mathcal{P}_{i}^{1-\alpha}$, where parameter $0<\alpha<1$ is the union's relative bargaining power, subject to constraints (2) by the wage $w_{i}$ and the profit share $s_{i}$, taking aggregate demand $y$ and the growth rate of consumption, $g$, as given.

Because there is a one-to-one correspondence between $w_{i}$ and $x_{i}$ through (6) and (24), we can replace $w_{i}$ by $x_{i}$ as the instrument of the maximization. Maximizing $\mathcal{U}_{i}^{\alpha} \mathcal{P}_{i}^{1-\alpha}$ by $x_{i}$ and $s_{i} \in[0,1]$ and noting the symmetry throughout all $i$, we obtain (see Appendix $A$ )

$$
\xi z(x)=g(\alpha) \text { with }\left\{\begin{array}{l}
g^{\prime}>0 \text { for } 0<\alpha<\bar{\alpha} \\
g^{\prime} \equiv 0 \text { for } \bar{\alpha} \leq \alpha \leq 1
\end{array}\right.
$$

where $\bar{\alpha} \in(0,1]$ is a constant. This result can be rephrased as follows:

Proposition 1 There exists a critical level of $\bar{\alpha} \in(0,1]$ of the relative union bargaining power $\alpha$ as follows:

(i) If unions are strong enough, $\alpha \geq \bar{\alpha}$, there is profit sharing and the the wage $w_{i}$ is chosen to maximize the present value of output (27). In such a case, labour market regulation has no effect on growth, $d g / d \alpha=0$.

(ii) If unions are not too strong, $\alpha<\bar{\alpha}$, there is no profit sharing, $s_{i}=0$ and $v_{i}=w_{i}$ for all $i$. In such a case, labour market regulation (i.e., the increase in $\alpha$ ) promotes economic growth, $d g / d \alpha>0$.

If unions are strong enough (i.e., if $\alpha$ close enough to one), they can claim a share of profits on the top of the wages. In such a case, relative union bargaining power determines the workers' profit share but it is in the interests of both parties to choose the base wage $w_{i}$ to maximize the discounted value of output. A change in relative union bargaining power has then no effect 
on employment or economic growth. If unions are relatively weak (i.e., if $\alpha$ not too close to one), there is no profit sharing and employment and $R \& D$ decisions depend on relative union bargaining power $\alpha$. Regulation (i.e., the increase in $\alpha$ ) then increases the wage $w_{i}$ relative to effort $E_{i}$. The increase in average labour cost $w_{i} / E_{i}$ decreases employment and firms escape this cost increase by transferring resources from production to $R \& D$. A higher level of $R \& D$ will lead to a higher growth rate.

\section{Welfare evaluation}

Now we examine the optimal level of labour market regulation. Because, by proposition 1 , regulation is totally ineffective for $\alpha \geq \bar{\alpha}$, we focus on the case $\alpha<\bar{\alpha}$ for which $s_{i}=0$ and $v_{i}=w_{i}$. With perfect symmetry through all firm-union pairs $i=1, \ldots, n$, we obtain $l_{i}=l, x_{i}=x, y_{i}=y$ and $v_{i}=w_{i}=w$. Given (18), the accumulation of knowledge in (23) takes then the form

$$
\dot{h} / h=z(x),
$$

and total consumption is determined by (see Appendix $B$ )

$$
c=h^{\xi} \varphi(x) .
$$

The government maximizes the welfare of the representative consumer (9) by labour market regulation/deregulation (i.e. by increasing/decreasing $\alpha$ ) subject to the consumption function (32) and the accumulation of knowledge (33). Since there is one-to-one correspondence from $\alpha$ to $x$ through (18) and (31), we can replace $\alpha$ by $x$ as the instrument of the maximization. The Hamiltonian corresponding to the government's problem is then given by

$$
\mathcal{F}=\frac{1}{1-\sigma}\left[c^{1-\sigma}-1\right]+\lambda z(x) h=\frac{1}{1-\sigma}\left[\varphi(x)^{1-\sigma} h^{(1-\sigma) \xi}-1\right]+\lambda z(x) h,
$$

where the co-state variable $\lambda$ evolves according to

$$
\dot{\lambda}=\rho \lambda-\frac{\partial \mathcal{F}}{\partial h}=[\rho-z(x)] \lambda-\xi \varphi(x)^{1-\sigma} h^{(1-\sigma) \xi-1}, \quad \lim _{t \rightarrow \infty} \lambda h e^{-\rho t}=0 .
$$

At each moment of time, the Hamiltonian (34) must be maximized. This produces the first-order condition $\partial \mathcal{F} / \partial x=\lambda h z^{\prime}+\varphi^{-\sigma} h^{(1-\sigma) \xi} \varphi^{\prime}=0$ or

$$
\lambda=-\varphi(x)^{-\sigma} h^{(1-\sigma) \xi-1} \varphi^{\prime}(x) / z^{\prime}(x) .
$$


Because the government has only one accumulating asset, it is always in the steady state where the level of employment, $x$, is constant. Equations (32) and (36) then yield $\dot{\lambda} / \lambda=[(1-\sigma) \xi-1] \dot{h} / h=[(1-\sigma) \xi-1] z$. Inserting this, (14), (36) and $g=\xi z$ from (31) into (35), we obtain

$$
[(1-\sigma) \xi-1] z=\dot{\lambda} / \lambda=\rho-z-\xi \varphi^{1-\sigma} h^{(1-\sigma) \xi-1} / \lambda=\rho-z+\xi z^{\prime} \varphi / \varphi^{\prime}
$$

and

$$
\xi z^{\prime} \varphi / \varphi^{\prime}=(1-\sigma) z \xi-\rho=(1-\sigma) g-\rho=g-r .
$$

Because the integral (9) converges only if $\rho<(1-\sigma) \dot{c} / c=(1-\sigma) g$, from equations (33) and (37) it follows that consumption and employment are positively associated, $\varphi^{\prime}>0$ and $\partial c / \partial x>0$. Noting this, (18), (31) and (33), we define the elasticity of the level of $R \& D, z$, with respect to consumption $c=\varphi h^{\xi}$ when the level of productivity, $h$, is kept constant, as:

$$
\theta \doteq\left|\frac{\partial z}{\partial c} \frac{c}{z}\right|=\left|\frac{\partial z}{\partial x} \frac{\partial x}{\partial c} \frac{c}{z}\right|=\left|\frac{z^{\prime} \varphi}{z \varphi^{\prime}}\right|=-\frac{z^{\prime} \varphi}{z \varphi^{\prime}}=-\frac{\xi z^{\prime} \varphi}{g \varphi^{\prime}}>0 .
$$

Inserting (37) into this definition, we obtain the growth rate maximizing the representative consumer's welfare, $g^{*}=r /(1+\theta)$. This, together with proposition 1 , leads to the following policy rule:

Proposition 2 The government should regulate (deregulate) the labour market as long as the growth rate $g$ is below (above) $g^{*} \doteq r /(1+\theta)$.

Inserting $r=\rho+\sigma g^{*}$ from (14) into $g^{*}=r /(1+\theta)$, we obtain $g^{*}=$ $\rho /(1-\sigma+\theta)$ and the following corollary:

Proposition 3 The lower the elasticity of $R \& D$ is with respect to consumption, $\theta$, the more likely regulation increases welfare (i.e., the more likely $\left.g<g^{*}\right)$.

Propositions 2 and 3 are explained in the final section. 


\section{Conclusions}

In this paper, efficiency wages, union-firm bargaining and profit sharing were incorporated into a unified framework of endogenous growth. We were interested in how regulation (deregulation), which strengthens (weakens) unions in bargaining, affects economic growth. An employee works the harder, the more more the wage in the firm exceeds the expected labour income outside the firm. A firm accumulates knowledge and increases its productivity by doing $R \& D$. In this framework, we obtain the following results.

Provided that union power is not initially too high, labour market regulation decreases employment and current consumption but fosters economic growth. When union bargaining position is improved, wages increase relative to a worker's effort and firms try to escape this cost increase through improved productivity, by increasing its $R \& D$. With larger $R \& D$, the economy will grow at a faster rate. If unions are strong enough, they can claim a share of profits on the top of their wages. Unions and firms then share the profit in fixed proportion to their relative bargaining power and maximize the discounted value of total income by the wage, so that labour market regulation will not affect $R \& D$ and growth.

The desirability of regulation or deregulation depends on whether economic growth is too fast or too slow from the welfare point of view. If this is too fast, the labour market should be deregulated to slow down technological change. Overly slow growth can be eliminated by labour market regulation. The higher the elasticity of $R \& D$ with respect to consumption (given the interest rate), the more likely regulation increases welfare. Consumption and $R \& D$ are produced from the same resources. The more a decrease in current consumption by one unit increases future consumption through larger $R \& D$ and a higher growth rate, the higher is the welfare-maximizing growth rate and the more likely actual growth should be promoted by regulation.

While a great deal of caution should be exercised when a highly stylized mathematical model is used to draw conclusions about the effects of regulation on growth, the following judgement nevertheless seems to be justified. Since the institutional specification of the labour market is significant for the outcome of regulation, in contrast to the OECD Jobs Study, strengthening competitive forces in the labour market may slow down economic growth. 


\section{Appendix}

A. The proof of result (31)

We deduce first two useful subresults. Given (27), we obtain

$$
\frac{\partial^{2} \log Y_{i}}{\partial x_{i} \partial y}=0
$$

Because there is symmetry through all $i$, in the macroeconomic equilibrium there must be $z_{i}=z, x_{i}=x, l_{i}=l, y_{i}=y$ and $v_{i}=v$. Given this, (10), (15), (18) and (23), we obtain

$$
g=\xi \frac{\dot{y}}{y}=\frac{\xi}{y} \sum_{k=1}^{n} \frac{\partial y}{\partial y_{k}} \dot{y}_{k}=\frac{\xi}{n} \sum_{k=1}^{n}\left(\frac{y}{y_{k}}\right)^{1 / \mu-1} z_{k},\left.\quad g\right|_{y_{k}=y}=\frac{\xi}{n} \sum_{k=1}^{n} z\left(x_{k}\right) .
$$

Given equations (4), (12), (16) and (28)-(30), we define a function

$$
\begin{aligned}
& \Gamma_{i}\left(s_{i}, x_{i}, g, y, \alpha\right) \doteq \log \left[\mathcal{U}_{i}^{\alpha} \mathcal{P}_{i}^{1-\alpha}\right]=\alpha \log \mathcal{U}_{i}+(1-\alpha) \log \mathcal{P}_{i} \\
& =\alpha \log \left[W_{i}\left(x_{i}, g, y\right)+s_{i} \Pi_{i}\left(x_{i}, g, y\right)\right]+(1-\alpha)\left[\log \Pi_{i}\left(x_{i}, g, y\right)+\log \left(1-s_{i}\right)\right] \\
& =\alpha \log \left[\left(1-s_{i}\right) W_{i}+s_{i} Y_{i}\right]+(1-\alpha) \log \left(Y_{i}-W_{i}\right)+(1-\alpha) \log \left(1-s_{i}\right) \\
& =\log Y\left(x_{i}, g, y\right)+\alpha \log \left[\left(1-s_{i}\right) \phi_{i}\left(x_{i}, g\right)+s_{i}\right]+(1-\alpha) \log \left[1-\phi_{i}\left(x_{i}, g\right)\right] \\
& \quad+(1-\alpha) \log \left(1-s_{i}\right) .
\end{aligned}
$$

The outcome of bargaining is obtained through maximizing the logarithm of the Nash product (40) s.t. $0 \leq s_{i} \leq 1$ by $x_{i}$ and $s_{i}$, keeping $g$ and $y$ constant. This is equivalent to the maximization of the Lagrangean

$$
\mathcal{L}_{i}=\Gamma_{i}\left(s_{i}, x_{i}, g, y, \alpha\right)+\chi_{1} s_{i}+\chi_{2}\left(1-s_{i}\right)
$$

subject to Kuhn-Tucker conditions

$$
\chi_{1} s_{i}=0, \quad \chi_{1} \geq 0, \quad \chi_{2}\left(1-s_{i}\right)=0, \quad \chi_{2} \geq 0 .
$$

Given (40), we obtain the first-order conditions for $s_{i}$ and $x_{i}$ as:

$$
\begin{aligned}
& \frac{\partial \mathcal{L}_{i}}{\partial s_{i}}=\frac{\partial \Gamma_{i}}{\partial s_{i}}+\chi_{1}-\chi_{2}=\frac{\alpha\left(1-\phi_{i}\right)}{\left(1-s_{i}\right) \phi_{i}+s_{i}}-\frac{1-\alpha}{1-s_{i}}+\chi_{1}-\chi_{2}=0, \\
& \partial \mathcal{L}_{i} / \partial x_{i}=\partial \Gamma_{i} / \partial x_{i}=0 .
\end{aligned}
$$


Consider first the case where

$$
\text { either } \alpha=1 \quad \text { or } \quad \frac{1-\alpha}{\alpha}=\frac{\left(1-s_{i}\right)\left(1-\phi_{i}\right)}{\left(1-s_{i}\right) \phi_{i}+s_{i}} \text {. }
$$

If $\alpha=1$, then (40), (41) and (42) produce

$$
\chi_{2}=\frac{1-\phi_{i}}{\left(1-s_{i}\right) \phi_{i}+s_{i}}+\chi_{1}>\chi_{1} \geq 0, \quad s=1, \quad \Gamma_{i}=\log Y_{i} .
$$

This means that the maximization of $(40)$ by $x_{i}$ is equivalent to the maximization of the present value of output, $Y_{i}$, by $x_{i}$ :

$$
x_{i}=\arg \max _{x_{i}} Y_{i}\left(x_{i}, g, y\right)
$$

Next, assume $\alpha<1$ and

$$
\frac{1-\alpha}{\alpha}=\frac{\left(1-s_{i}\right)\left(1-\phi_{i}\right)}{\left(1-s_{i}\right) \phi_{i}+s_{i}} .
$$

This, (29) and (40) yield $\left(1-s_{i}\right) \phi_{i}+s_{i}=\alpha,\left(1-s_{i}\right)\left(1-\phi_{i}\right)=1-\alpha$ and

$$
\Gamma_{i}=\log Y_{i}\left(z_{i}, g, y\right)+\text { constants. }
$$

Again, the maximization of (40) by $x_{i}$ is equivalent to the maximization of $Y_{i}$ by $x_{i}$. We conclude that if (43) holds, then $x_{i}$ is determined by (44). Noting this and the first-order condition for $x_{i}$, we can define a constant

$$
\bar{\alpha}=\inf \left\{\alpha \mid \partial \mathcal{L}_{i} / \partial x_{i}=0 \text { and (43) holds }\right\} \leq 1 .
$$

Because in the model there is symmetry through all $i$, this yields

$$
x_{i}=x=\arg \max _{x} Y_{i}(x, g, y) \text { for } \alpha \geq \bar{\alpha} .
$$

From (39) and (47) it follows that inputs $x_{i}$ for all $i$ and the growth rate $g$ are independent of $\alpha$ for $\alpha \geq \bar{\alpha}$.

If $\alpha \rightarrow 0$, then given (41) and (42) we obtain

$$
\chi_{1}=(1-\alpha) /\left(1-s_{i}\right)+\chi_{2}>\chi_{2} \geq 0, \quad s_{i}=0 .
$$

Hence, for sufficiently small values of $\alpha$ condition (43) cannot hold. Given this result and (46), there must be $\bar{\alpha}>0$. Because condition (44) holds for $\bar{\alpha} \leq \alpha \leq 1$, the equilibrium of the system is independent of $\alpha$ and

$$
d z / d \alpha=0 \text { for } \bar{\alpha} \leq \alpha \leq 1 \text {. }
$$


Finally, consider the case

$$
0<\alpha<\bar{\alpha}
$$

It follows that (43) does not hold and

$$
\alpha<1, \quad \frac{1-\alpha}{\alpha} \neq \frac{\left(1-s_{i}\right)\left(1-\phi_{i}\right)}{\left(1-s_{i}\right) \phi_{i}+s_{i}} .
$$

holds. Because $s_{i}=1$ is in contradiction with (50), $s_{i}<1$ obtains. From $s_{i}<1,(41),(42)$ and (50) it follows

$$
\chi_{2}=0, \quad \chi_{1}=\frac{1-\alpha}{1-s_{i}}-\frac{\alpha\left(1-\phi_{i}\right)}{\left(1-s_{i}\right) \phi_{i}+s_{i}}>0, \quad s_{i}=0 .
$$

Given $s_{i}=0$, the function (40) takes the form

$\Gamma_{i}\left(0, x_{i}, g, \alpha, y\right)=\log Y\left(x_{i}, g, y\right)+\alpha \log \phi_{i}\left(x_{i}, g\right)+(1-\alpha) \log \left[1-\phi_{i}\left(x_{i}, g\right)\right]$, and the remaining first-order condition the form

$$
\frac{\partial \Gamma_{i}}{\partial x_{i}}=\frac{\partial \log Y_{i}\left(x_{i}, g, y\right)}{\partial x_{i}}+\frac{\alpha / \phi_{i}\left(x_{i}, g\right)-1}{1-\phi_{i}\left(x_{i}, g\right)} \frac{\partial \phi_{i}\left(x_{i}, g\right)}{\partial x_{i}}=0 .
$$

This, (26) and (38) yield

$$
\frac{\partial^{2} \Gamma_{i}}{\partial x_{i} \partial c}=\frac{\partial^{2} \log Y_{i}}{\partial x_{i} \partial c}=0, \quad \frac{\partial^{2} \Gamma_{i}}{\partial x_{i} \partial \alpha}=\frac{1}{\left(1-\phi_{i}\right) \phi_{i}} \frac{\partial \phi_{i}}{\partial x_{i}}<0 .
$$

Noting (26), (52) and the second-order condition $\partial^{2} \Gamma_{i} / \partial x_{i}^{2}<0$, and differentiating the first-order condition (51) totally, we define the function

$$
x_{i}=\Psi(\alpha, g) \text { with } \frac{\partial \Psi}{\partial \alpha}=-\frac{\partial^{2} \Gamma_{i}}{\partial x_{i} \partial \alpha} / \frac{\partial^{2} \Gamma_{i}}{\partial x_{i}^{2}}<0 \text { for } 0<\alpha<\bar{\alpha} .
$$

Noting the symmetry over $i$ and inserting the right-hand equation of (39) into the functions (53), we obtain a system of $n$ equations

$$
\Delta_{i}=x_{i}-\Psi(\alpha, g)=x_{i}-\Psi\left(\alpha, \frac{\xi}{n} \sum_{k} z\left(x_{k}\right)\right)=0 \text { for } j=1, \ldots, n
$$

with endogenous variables $x_{1}, \ldots, x_{n}$. Differentiating the system (54), we obtain the coefficient matrix

$$
\left(\partial \Delta_{i} / \partial x_{k}\right)_{n \times n}
$$


The reaction function for each sector $i$ is given by (54). With perfect symmetry over all sectors $i$, the sufficient conditions for the stability of the equilibrium imply that the coefficient matrix (55) is subject to diagonal dominance. ${ }^{8}$ Noting the symmetry over $x_{k}$ for $k \neq i$ as well as equations (54), we obtain the diagonal dominance into the form

$$
\begin{aligned}
0 & <\frac{\partial \Delta_{i}}{\partial x_{i}} \pm \sum_{k \neq i} \frac{\partial \Delta_{i}}{\partial x_{k}}=1-\frac{\xi}{n} \frac{\partial \Psi}{\partial g} z^{\prime}\left(x_{i}\right) \pm \frac{\xi}{n} \sum_{k \neq i} \frac{\partial \Psi}{\partial g} z^{\prime}\left(x_{k}\right) \\
& =1-\left[\frac{1}{n} \pm\left(1-\frac{1}{n}\right)\right] \xi \frac{\partial \Psi}{\partial g} z^{\prime} \text { for } k \neq i .
\end{aligned}
$$

This implies $\xi z^{\prime} \partial \Psi / \partial g<1$. Noting the symmetry throughout all $k$, we obtain $x_{k}=x$ for all $k$ and $z(x)=g / \xi$. Functions (53) can then be transformed into $\Psi(\alpha, g)=x=z^{-1}(g / \xi)$, where $z^{-1}$ is the inverse function of $z(x)$. Differentiating this equation and noting (18) and (53) and $\xi z^{\prime} \partial \Psi / \partial g<1$, we obtain $\partial \Psi / \partial g>1 /\left(\xi z^{\prime}\right)$ and

$$
\xi z=g(\alpha) \text { with } g^{\prime} \doteq \frac{d g}{d \alpha}=\frac{\partial \Psi}{\partial \alpha} /\left(\frac{1}{\xi z^{\prime}}-\frac{\partial \Psi}{\partial g}\right)>0 \text { for } 0<\alpha<\bar{\alpha} .
$$

Results (48) and (56) can be summarized as (31).

\section{B. The proof of result (33)}

Noting symmetry $l_{i}=l, x_{i}=x, z_{i}=z, y_{i}=y$ and $v_{i}=w_{i}=w$ and using equations (11), (12) and (26), we obtain

$$
p_{i}=1 / n, \quad \varpi L=\xi y /(1-\xi), \quad v=w=\phi_{i} y /(n l) .
$$

Given these and (18), equations (1), (5), (6), (7) and (31) take then the form

$$
\begin{aligned}
& L+n l=N, \quad l=x_{i} / E_{i}=x / E\left(v / v_{-i}\right), \quad g=\xi z \\
& \frac{v_{-i}}{v}=\frac{1}{N-l}\left[(n-1) l+\frac{\varpi}{v} L\right]=\frac{1}{N-l}\left[(n-1) l+\frac{\xi}{1-\xi} \frac{n l}{\phi_{i}(z, g)}\right] \\
& \quad=\frac{1}{N / l-1}\left[n-1+\frac{\xi}{1-\xi} \frac{n}{\phi_{i}(Z, \xi Z)}\right] .
\end{aligned}
$$

In the system (58), there are four equations, four endogenous variables $L$, $l, g$ and $v / v_{-i}$ and one exogenous variable $x$. By the comparative statics of

\footnotetext{
${ }^{8}$ See, for example, Dixit (1986), p. 117. Here, the diagonal term 1 is positive, so that the inequality must be greater than zero.
} 
this system, we can define $L$ as a function of $x$. Equations (10), (16), (17) and (18) as well as the function $L(x)$ produce

$$
c=y^{\xi} L^{1-\xi}=h^{\xi} m(x)^{\xi} L(x)^{1-\xi}=h^{\xi} \varphi(x) \text { with } \varphi(x) \doteq m(x)^{\xi} L(x)^{1-\xi} .
$$

\section{References:}

Binmore, K., Rubinstein, A. and Wolinsky, A. (1986). The Nash bargaining solution in economic modelling. Rand Journal of Economics 17, 176-188.

Blanchard, O. and Giavazzi, F. (2001). Macroeconomic effect of regulation and deregulation in goods and labor markets. Working paper 01-02, Department of Economics, MIT.

Dixit, A. (1986). Comparative statics for oligopoly, International Economic Review 2\%. 107-122.

Garino, G. and Martin, C. (2000). Efficiency wages and union-firm bargaining. Economics Letters 69, 181-185.

The OECD Jobs Study; Evidence and Explanations Part II. Paris 1994.

Palokangas, T. (1996). Endogenous growth and collective bargaining. Journal of Economic Dynamics and Control 20, 925-944.

Palokangas, T. (2000). Labour Unions, Public Policy and Economic Growth. Cambridge (U.K.): Cambridge University Press.

Peretto, P.F. (1998). Market power, growth and unemployment. Duke Economics Working Paper 98-16.

Romer, P.M. (1990). Endogenous technological change. Journal of Political Economy 98, S71-S102.

Smulders, S. and Van de Klundert, T. (1995). Imperfect competition, concentration and growth with firm-specific $R \& D$. European Economic Review 39, 139-160.

Solow, R. (1979). Another possible source of wage stickiness. Journal of Macroeconomics 1, 79-82.

Summers, L.H. (1988). Relative wages, efficiency wages and keynesian unemployment. American Economic Review 78, 383-388.

Van Schaik, A.B.M. and De Groot, H.L.F. (1998). Unemployment and endogenous growth. Labour 12, 189-219. 


\section{IZA Discussion Papers}

\begin{tabular}{|c|c|c|c|c|}
\hline No. & Author(s) & Title & Area & Date \\
\hline 705 & $\begin{array}{l}\text { G. Brunello } \\
\text { D. Checchi }\end{array}$ & School Quality and Family Background in Italy & 2 & $01 / 03$ \\
\hline 706 & $\begin{array}{l}\text { S. Girma } \\
\text { H. Görg }\end{array}$ & $\begin{array}{l}\text { Blessing or Curse? Domestic Plants' Survival } \\
\text { and Employment Prospects after Foreign } \\
\text { Acquisitions }\end{array}$ & 1 & $01 / 03$ \\
\hline 707 & $\begin{array}{l}\text { C. Schnabel } \\
\text { J. Wagner }\end{array}$ & $\begin{array}{l}\text { Trade Union Membership in Eastern and } \\
\text { Western Germany: Convergence or } \\
\text { Divergence? }\end{array}$ & 3 & $01 / 03$ \\
\hline 708 & $\begin{array}{l}\text { C. Schnabel } \\
\text { J. Wagner }\end{array}$ & $\begin{array}{l}\text { Determinants of Trade Union Membership in } \\
\text { Western Germany: Evidence from Micro Data, } \\
1980-2000\end{array}$ & 3 & $01 / 03$ \\
\hline 709 & $\begin{array}{l}\text { L. Danziger } \\
\text { S. Neuman }\end{array}$ & $\begin{array}{l}\text { Delays in Renewal of Labor Contracts: Theory } \\
\text { and Evidence }\end{array}$ & 1 & $02 / 03$ \\
\hline 710 & $\begin{array}{l}\text { Z. Eckstein } \\
\text { Y. Weiss }\end{array}$ & $\begin{array}{l}\text { On the Wage Growth of Immigrants: Israel, } \\
1990-2000\end{array}$ & 2 & $02 / 03$ \\
\hline 711 & C. Ruhm & Healthy Living in Hard Times & 3 & $02 / 03$ \\
\hline 712 & $\begin{array}{l}\text { E. Fehr } \\
\text { J. Henrich }\end{array}$ & $\begin{array}{l}\text { Is Strong Reciprocity a Maladaptation? On the } \\
\text { Evolutionary Foundations of Human Altruism }\end{array}$ & 5 & $02 / 03$ \\
\hline 713 & $\begin{array}{l}\text { I. Gang } \\
\text { J. Landon-Lane } \\
\text { M. S. Yun }\end{array}$ & $\begin{array}{l}\text { Does the Glass Ceiling Exist? A Cross-National } \\
\text { Perspective on Gender Income Mobility }\end{array}$ & 2 & $02 / 03$ \\
\hline 714 & M. Fertig & $\begin{array}{l}\text { Educational Production, Endogenous Peer } \\
\text { Group Formation and Class Composition - } \\
\text { Evidence From the PISA } 2000 \text { Study }\end{array}$ & 6 & $02 / 03$ \\
\hline 715 & $\begin{array}{l}\text { E. Fehr } \\
\text { U. Fischbacher } \\
\text { B. von Rosenbladt } \\
\text { J. Schupp } \\
\text { G. G. Wagner }\end{array}$ & $\begin{array}{l}\text { A Nation-Wide Laboratory Examining Trust and } \\
\text { Trustworthiness by Integrating Behavioral } \\
\text { Experiments into Representative Surveys }\end{array}$ & 7 & $02 / 03$ \\
\hline 716 & $\begin{array}{l}\text { M. Rosholm } \\
\text { L. Skipper }\end{array}$ & $\begin{array}{l}\text { Is Labour Market Training a Curse for the } \\
\text { Unemployed? Evidence from a Social } \\
\text { Experiment }\end{array}$ & 6 & $02 / 03$ \\
\hline 717 & $\begin{array}{l}\text { A. Hijzen } \\
\text { H. Görg } \\
\text { R. C. Hine }\end{array}$ & $\begin{array}{l}\text { International Fragmentation and Relative Wages } \\
\text { in the UK }\end{array}$ & 2 & $02 / 03$ \\
\hline 718 & E. Schlicht & Consistency in Organization & 1 & $02 / 03$ \\
\hline 719 & $\begin{array}{l}\text { J. Albrecht } \\
\text { P. Gautier } \\
\text { S. Vroman }\end{array}$ & $\begin{array}{l}\text { Equilibrium Directed Search with Multiple } \\
\text { Applications }\end{array}$ & 3 & $02 / 03$ \\
\hline 720 & T. Palokangas & $\begin{array}{l}\text { Labour Market Regulation, Productivity- } \\
\text { Improving R\&D and Endogenous Growth }\end{array}$ & 3 & $02 / 03$ \\
\hline
\end{tabular}

An updated list of IZA Discussion Papers is available on the center's homepage www.iza.org. 